\title{
O CONCEITO DE LEI EM HANNAH ARENDT
}

\author{
THE CONCEPT OF LAW IN HANNAH ARENDT
}

\author{
SÔNIA MARIA SCHIO ${ }^{1}$ \\ (UFPel / Brasil) \\ CLÁUDIA CARNEIRO PEIXOTO ${ }^{2}$ \\ (UFPel / Brasil)
}

\begin{abstract}
RESUMO
Hannah Arendt (1906-1975) embora não tenha sistematizado uma Teoria ou Filosofia do Direito escreveu, em várias obras, apontamentos acerca dos Direitos Humanos e sobre a lei. E é nesse sentido que se pode perguntar: qual é a concepção de lei em Arendt? Na hipótese a ser desenvolvida, Arendt parte de uma crítica às Declarações de Direitos Humanos, pensando a lei por um viés republicano, ligado à política e ao cidadão participante e responsável.
\end{abstract}

Palavras-chave: Hannah Arendt, Direitos Humanos, lei, política, cidadania.

\begin{abstract}
Abstract: Although not having organized a theory or philosophy of law, Hannah Arendt (1906-1975) conceived, in several works, notes on Human Rights and the law. And it is this sense that we can ask: what is the conception of law in Arendt? In the hypothesis to be developed, Arendt part of a critics the Declarations of Human Rights, thinking the law by a Republican bias, linked to politics and at citizen participating and responsible.
\end{abstract}

Keywords: Hannah Arendt, Human Rights, law, politics, citizenship.

Hannah Arendt (1906-1975) foi uma pensadora da política, tanto em suas abordagens teórico-filosóficas quanto em sua compreensão dos eventos empíricos. Dessa perspectiva partem seus questionamentos sobre os eventos marcantes do século $\mathrm{XX}$ e suas reflexões relativas ao Direito e à lei, os quais, ao lado da categoria do poder, constituem os pilares conceituais que, desde a Antiguidade sustentam os vários tipos de governos (cf. ARENDT, 2011b, p. 275). Arendt não escreveu qualquer obra em que sistematizasse suas concepções acerca da Filosofia do Direito ou em que se detivesse apenas sobre o campo do Direito. Entretanto, pode-se encontrar este enfoque em recortes esparsos, com maior especificidade em Origens do Totalitarismo, A Condição Humana, Crises da República, Sobre a Revolução entre outros.

Em Origens do Totalitarismo, ela aborda a questão dos Direitos Humanos sob o pano de fundo do Fenômeno Totalitário, mais detidamente, o Nazista, o qual a levou, bem como muitos 
outros pensadores, em especial após a Segunda Guerra Mundial (1939-1945), a guiarem suas reflexões pela perplexidade diante de fatos como a "produção de cadáveres em série".

A partir de uma longa análise que perpassa a história, a política, a sociologia e o âmbito cultural (cf. ARENDT, 1989, p. 444-445, por exemplo), ela enfatiza que há a necessidade de que cada pessoa tenha o "direito a ter direitos" no âmbito de uma proteção internacional - e não somente como consequência de uma dada nacionalidade - como único modo de preservar a cidadania e, por conseguinte, a dignidade humana. Nesse viés, a apreciação que Arendt empreende dos "códigos" garantidores dos "direitos humanos", desde a Independência dos Estados Unidos (1776) até a Declaração Universal dos Direitos Humanos (1948), ${ }^{3}$ constitui uma crítica ao caráter "abstrato" dos indivíduos a serem protegidos e amparados. A crítica arendtiana fixa-se na ineficácia dos Direitos Humanos quando confrontados com situações extremas, como a vivenciada em Estados Totalitários. Segundo ela (1989, p. 498):

Isso só pôde acontecer porque os Direitos do Homem, apenas formulados mas nunca filosoficamente estabelecidos, apenas proclamados mas nunca politicamente garantidos, perderam, em sua forma tradicional, toda a validade.

Dito de outra forma, a defesa dos Direitos Humanos, estabelecida por meio dos princípios norteadores das Declarações de Direitos, não foi politicamente garantida. As Declarações proclamadas e positivadas por regras e normas constitucionais não foram suficientes para impedir o extermínio em massa de judeus, ciganos e outros, o que ficou demonstrado pelo Nazismo, pois os crimes cometidos por esta forma de dominação suplantaram qualquer tipologia positivada. ${ }^{4}$

A incapacidade dos códigos de Direitos Humanos de salvaguardar a vida e a dignidade dos seres humanos, segundo Arendt, deveu-se ao fato de, na Modernidade, os indivíduos terem se tornado "povo", descaracterizando-se como pessoas individuais e reais. A pessoa em si, abstrata, torna-se vulnerável à perda da personalidade jurídica, da sua identidade e singularidade, o que ocorreu largamente nos campos de concentração e de extermínio, tanto Nazistas como Stalinistas.

Por sua postura quanto aos Direitos Humanos, Arendt foi criticada, tendo repercutido entre seus comentadores (por exemplo, ROVIELLO, 1987 e LAFER, 1988), que trataram de esclarecer que a autora não era "contra" a existência das Declarações de Direitos Humanos. O que ela problematizou foi a justificação e a eficácia das Declarações, pois mesmo após 1948 - e até os dias de hoje - vive-se sob o signo da violação e do desrespeito aos direito ditos "humanos". Desta feita, sob o prisma arendtiano, a abstração do sujeito de direito provoca a abertura para o ethic@-Florianópolis v. 11, n. 3, p.289-297, Dez. 2012. 
descarte de vidas como supérfluas, uma vez que a legalidade calcada em abstrações é insuficiente para coibir os abusos de um governo tirânico ou totalitário contra os indivíduos. Isto é, basta que sejam elencados motivos aparentemente razoáveis - como na contemporaneidade, o "terrorismo" - para que os direitos humanos deixem de ser efetivos e possam ser "esquecidos" ou contornados, o que concretamente significa serem violados em prol de ideias como a de “justiça”, por exemplo, o que corrobora o insucesso da acepção naturalista das Declarações de Direitos Humanos.

Por outro lado, a distinção entre legalidade e legitimidade à luz dos regimes totalitários evidencia que estes não precisavam eliminar as leis, restringindo-se a torna-las flexíveis e inoperantes com base em princípios transcendentes, absolutos e inquestionáveis como as leis da natureza - no caso do Nazismo - e da História - no caso do Stalinismo - (cf. ARENDT, 2009, p. 147). A deformação do "humano" em função da Natureza ou da História converte a humanidade em raças e em unidades naturais-orgânicas (cf. ARENDT, 2005b, p. 29). Esse quadro sugere à Arendt uma concepção de humanidade, não como a encarnação de um homem abstrato, manipulável de acordo com ideologias dominantes, mas na acepção de pluralidade capaz de assegurar, no âmbito internacional, uma cidadania comum a todos e sedimentada no mais elementar que é o "direito a ter direito". Ou como asseverado por ela (1989, p. 332):

\footnotetext{
Esta nova situação, na qual a "humanidade" assumiu de fato um papel antes atribuído à natureza ou à história, significaria nesse contexto que o direito a ter direito, ou o direito de cada indivíduo de pertencer à humanidade, deveria ser garantido pela própria humanidade.
}

Estas considerações convergem para o desenvolvimento da ideia do que sejam as leis em Arendt, as quais (1989, p. 515) "destinam-se primariamente a funcionar como elementos estabilizadores para os movimentos do homem, que são eternamente mutáveis". Esta mutabilidade é parte do movimento ininterrupto dos assuntos humanos, denominação de Arendt para as atividades e temas que reúnem os seres humanos em um espaço chamado de "público", que se materializa por meio da ação e que tem na condição humana da natalidade a potencialidade da chegada - positiva ou não - do novo. A novidade é acrescida ao mundo pelos "novatos", isto é, pelos seres humanos que passam a integrar o mundo humano pelo fato de nascerem, expondo-o a constante ameaça, assim como às instituições estabelecidas (cf. ARENDT, 2010, p. 308). 
Como já acentuado, a autora rejeita quaisquer condicionantes como a natureza ou a história (1989, p. 324-325), a fim de centrar-se no "homem", visando a deixar intacta a pessoa humana. Deste modo, a lei atua como um invólucro do "eu", revestindo o homem de uma personalidade jurídica. Consequentemente, não é o homem em sua nudez ou abstração que adentra um tribunal para pleitear seus direitos ou responder por seus atos, mas um sujeito portador de direitos e obrigações (cf. ARENDT, 2011, p. 141). Para embasar sua tese, Arendt retoma o debate sob a perspectiva da Antiguidade greco-romana.

Na polis grega, exemplo caro à autora, a lei - nomos - era concebida como um "muro", 6 fronteira que delimitava o espaço em que os cidadãos estavam abrigados e podiam vivenciar a política (cf. ARENDT, 1989, p. 444). A lei instituía um “espaço” entre os homens, pois lhes concedia um "estatuto jurídico" que os habilitava a fazer parte de um espaço público ou comum, na qualidade de cidadãos. Este espaço era regido pela igualdade que, por sua vez, não era oriunda de uma "natureza humana", mas derivava de uma convenção artificial, ou seja, um predicado "do mundo feito pelos homens" (ARENDT, 2011, p. 59).

Para Arendt, a igualdade, convencionada pelas leis, possibilita que a condição humana da pluralidade se concretize, pois apenas por meio desta igualdade vivida no domínio público é que os homens podem se distinguir na pluralidade. Nos termos da autora (ARENDT, 2010, p. 220): "No homem, a alteridade, que ele compartilha com tudo o que existe, e a distinção, que ele partilha com tudo o que vive, torna-se a unicidade, e a pluralidade humana é a paradoxal pluralidade de seres únicos". Na polis cada um podia participar ativa e diretamente do poder por meio do discurso, anuindo ou discordando e, acima de tudo, vivendo "como um ser distinto e único entre iguais" (idem, 2010, p 223).

A principal limitação de tal "vida política" está na quantidade daqueles que eram tidos como cidadãos, e não na qualidade. A primeira, segundo Arendt, precisa ser ampliada e o “caminho" é a política. Para tanto, ela se serve das concepções de Montesquieu, quando esse trata das "instituições", inserindo-se nesse contexto como uma pensadora da República. Nesse viés, a república, entendida por ela como aquela que, ao colocar os três poderes em correlação e em corresponsabilidade, bem como em igualdade, é a que lhe parece ser a mais adequada ao mundo contemporâneo, contrariando tanto Rousseau quanto Kant. O segundo ponto, vale dizer, a qualidade da experiência política legada por eles, precisa ser deixada no horizonte, como um modelo.

ethic@-Florianópolis v. 11, n. 3, p. 289 -297, Dez. 2012. 
A lex romana, por seu turno, tinha como base a res publica, isto é, o bem coletivo. ${ }^{7}$ A lei era instaurada a partir de uma discussão em conjunto, ${ }^{8}$ naquilo que se denomina atualmente de "pacto". Cícero é um representante dessa forma de conceber a vida política, momento em que a oratória, o falar bem em público, torna-se importante, junto à retórica e à filosofia. Para Arendt (apud AMIEL, 2007, p. 80), a política e, consequentemente, a lei romana, baseavam-se na tríade: autoridade, tradição e religião, que personificava a crença no caráter sagrado da fundação de Roma. Desta sacralidade da fundação emergia a autoridade mantida pela tradição. Observe-se que, na contemporaneidade, a tríade romana foi substituída pela crença no progresso e no futuro infindável (cf. ARENDT, 2009, p. 98).

No tocante à Idade Média, apesar da aparência de que Arendt pouco se valeu de seus conteúdos quanto à política, pode-se afirmar que ela extraiu o importante conceito de "amor" de Agostinho, transformado-o em amor mundi, o qual somado à humanitas de Cícero permitiramlhe direcioná-los à política: o amor pelo mundo e pelo homem é obtido somente quando é possível viver organizado politicamente com e entre iguais, os outros seres humanos, partilhando o mesmo espaço físico, a Terra. Por isso, os homens precisam preservar o mundo, legando-o às gerações vindouras. Outro pensador desse período, mesmo que mais tardio, e que não pode ser contornado é Maquiavel, cuja contribuição ao pensamento arendtiano centra-se, acima de tudo, na concepção da vida política como uma junção da virtù com a fortù. Ou seja, para que haja uma vivência política autêntica é necessário um caráter correto e um contexto propício.

A Idade Moderna propicia à Arendt importantes referências, entre as quais pode-se destacar aquelas apropriadas de Kant, como a questão dos juízos determinantes e reflexionantes ou reflexivos -, presentes na obra Crítica da faculdade do juízo, sem os quais a lei não existiria. Os primeiros são aqueles comumente utilizados na aplicação da lei: i) do geral, a lei, conhecida; ii) o caso particular em questão; e a iii) dedução - lógica - da conclusão. Os juízos reflexionantes, por seu turno, são de difícil aplicação, mesmo na vida cotidiana, pois a busca de um geral inexistente para julgar, apesar de ser possível para Kant e Arendt, não é uma tarefa simples. Ainda quanto às convergências com Kant, podem-se citar os temas da publicidade, da comunicabilidade, entre outros, assim como existem divergências, por exemplo, em relação à atitude arendtiana frente à rigidez dos imperativos kantianos. Outra diferença relevante nos dois autores encontra-se no conceito de História: para Arendt não há um "fio condutor", progresso ou processo na História, devido ao valor que ela concede à ação humana. 
Nesse contexto, a lei, para Arendt, é tanto um "abrigo" 9 que protege e que assegura o espaço para a política, quanto a que permite a formação de "redes de comunicação" (cf. ARENDT, 1989, p. 517). Para possuir legitimidade, a lei não pode advir de algo distinto do homem: ela precisa de seu consentimento efetivo. E isso é um problema autenticamente político, com resultados inesperados advindos da ação e, portanto, sujeitos à mudança, devido à natalidade. Como teoriza Arendt (2011b, p. 277): “Cada novo nascimento ameaça a continuação da polis, pois em cada novo nascimento um novo mundo potencialmente vem a existir".

À guisa de "considerações finais", pode-se aduzir que a legitimidade arendtiana filia-se a uma visão de cunho republicano, o que implica em afirmar que o papel da lei de ordenar, regular e proteger exige a preexistência de categorias como a autoridade e o poder, e que terá como ressonância uma cidadania ativa, em que todos são a um só tempo partícipes e responsáveis pela efetivação das leis. Em outras palavras, todos os homens são igualmente "poderosos" e não necessitam da intervenção ou mediação de princípios transcendentes, como a Natureza ou a História (cf. ARENDT, 2011b, p. 285). Assim, o conceito de lei em Arendt está calcado no ser humano, real e participante na comunidade, cuja dignidade não advém do nascimento, mas de sua entrada no mundo como um ser humano. O mundo, então, é uma criação, uma atuação na physis a partir de trabalho dos homens, da elaboração de artefatos, entre eles a lei que, por sua vez, delimita o espaço público e político, conferindo-lhe a igualdade na pluralidade, o respeito à diferença, pois deste modo o humano é entendido como portador de dignidade exclusivamente por ser humano, que Arendt radica na dimensão mais elementar do "direito a ter direito". 


\section{Notas}

1 Professora Adjunta do Curso de Graduação e do Mestrado em Filosofia da UFPel; e-mail: soniaschio@hotmail.com.

${ }^{2}$ Mestranda em Filosofia Política pela UFPel; e-mail:dianoia11@hotmail.com.

3 Arendt distingue a Declaração de Direitos americana da Declaração dos Direitos do Homem francesa. Na Declaração francesa, os direitos são "inerentes à natureza do homem", sem relação alguma com seu estatuto político, em uma tentativa de "reduzir a política à natureza"; ao passo que, a Declaração americana "pretendia instituir formas de controle permanentes a todo poder político e, portanto, pressupunha a existência de um corpo político e o funcionamento do poder político" (ARENDT, 2011, p. 150-151).

${ }^{4}$ Isto restou evidenciado nos julgamentos que ocorreram em Nuremberg e no Caso Eichmann, que denotaram a falência dos paradigmas norteadores das instâncias de justificação e de aplicabilidade do Direito (cf. LAFER, 1988, p. 77).

${ }^{5}$ A prisão de Guantánamo é um exemplo de violação aos Direitos Humanos como prova da ineficácia destes mesmos direitos em situações em que os "motivos" são aparentemente "suficientes" para embasar as arbitrariedades.

6“A lei é, por assim dizer, algo por meio de que a polis ingressa em seu viver, algo que ela não pode abolir sem perder sua identidade e cuja violação é um ato de hybris, a transgressão de um limite interposto à própria vida. A lei não é válida fora da polis, seu poder vinculante só se aplica ao espaço que ela encerra e delimita. Mesmo para Sócrates, infringir a lei e ultrapassar as fronteiras da polis são, literalmente a mesma coisa" (ARENDT, 2009, p. 243).

${ }^{7}$ Ao expor a relevância da lei para conferir estabilidade aos negócios humanos, a autora deseja resgatar dos gregos antigos a noção de lei mural, nomos, e dos romanos, a lex no sentido de fundação e aliança, respectivamente. Estas caracterizações da lei são essenciais e estão entrelaçadas à esfera pública e sua importância tanto entre os gregos quanto entre os romanos, como torna patente a autora (ARENDT, 2004a, p. 66). Segundo ela, a polis era, para os gregos, o que a res publica foi para os romanos: a garantia contra a futilidade da vida individual, o espaço protegido contra essa futilidade e reservado à relativa permanência, senão à imortalidade, dos mortais.

${ }^{8}$ A diferença, em Roma, entre a pessoa e o cidadão também era significativa: “a distinção entre o indivíduo privado em Roma e o cidadão romano residia no fato de que este último tinha uma 'persona', uma personalidade jurídica, como diríamos; era como se a lei lhe tivesse atribuído o papel que deveria desempenhar no palco público, mas com a condição de que sua voz se fizesse ouvir” (ARENDT, 2011, p. 148).

${ }^{9}$ Ou em uma versão negativa: “a ausência de lei é insuportável aos indivíduos, pois destrói a segurança fornecida pela personalidade jurídica. As normas jurídicas por mais injustas que possam ser, estabilizam a vida humana, porque contém critérios, e esses servem de limite, de parâmetro às ações, seja à população, seja aos governantes" (SCHIO, 2006, p. 48). 


\section{Referências Bibliográficas}

ADEODATO, João Maurício Leitão. O problema da legitimidade: no rastro do pensamento de Hannah Arendt. Rio de Janeiro: Forense Universitária, 1989a.

AGAMBEN, Giorgio. Estado de exceção. Trad. Iraci D. Poleti. São Paulo: Boitempo, 2004. (Coleção Estado de Sítio)

AMIEL Anne. Le vocabulaire de Hannah Arendt. Paris: Ellipses, 2007.

ARENDT, Hannah. As Origens do Totalitarismo - Antissemitismo, Imperialismo, Totalitarismo. Trad. Roberto Raposo. São Paulo: Companhia das Letras, 1989.

. Eichmann em Jerusalém: um relato sobre a banalidade do mal. Trad. José Rubens Siqueira. São Paulo: Companhia das Letras, 1999.

. A dignidade da política. Rio de Janeiro: Relume-Dumará, 1993.

. A Condição Humana. Trad. Roberto Raposo, posfácio de Celso Lafer. 10 ed. Rio de Janeiro: Forense Universitária, 2004a.

. Crises da República. Trad. José Volkmann. 2 ed., São Paulo: Nova Perspectiva, 2004b.

. Compreender: formação, exílio e totalitarismo (ensaios - 1930-1954). (Trad. Denise Bottmann; organização, Introdução e notas Jerome Kohn) São Paulo/Belo Horizonte: Companhia das Letras/Editora UFMG, 2008.

. A promessa da política. Organização e introdução de Jerome Kohn. Trad. Pedro Jorgensen Jr. 2 ed., Rio de Janeiro: DIFEL, 2009.

A Condição Humana. Trad. Roberto Raposo. Revisão técnica e apresentação de Adriano Correia. 11 ed., Rio de Janeiro: Forense Universitária, 2010.

. Sobre a Revolução. Apresentação Jonathan Schell e trad. de Denise Bottmann. São Paulo: Companhia das Letras, 2011.

. A grande tradição in $\mathbf{O}$ que nos faz pensar. Trad. de Paulo Eduardo Bodziak e Adriano Correia. Cadernos do Departamento de Filosofia da PUC-Rio, v. 29, maio de 2011. (272-298)

BEINER, Ronald. Hannah Arendt et la faculté de juger. ARENDT, Hannah. Juger - sur la philosophie politique de Kant, Paris : Seuil, 2003. (131-221)

D’ALLONES, Le courage de juger ; ARENDT, Hannah. Juger - sur la philosophie politique de Kant, Paris : Seuil, 2003. (222-244) 
KANT, Immanuel. À paz perpétua e outros opúsculos. Lisboa: Edições 70, 1988.

. Crítica da faculdade do juízo. Rio de Janeiro: Forense Universitária, 1993.

LAFER, Celso. A reconstrução dos direitos humanos - Um diálogo com o pensamento de Hannah Arendt. São Paulo: Companhia das Letras, 1988.

. Hannah Arendt - Pensamento, persuasão e poder. 2 ed., revista e ampliada. São Paulo: Paz e Terra, 2003.

MONTESQUIEU, Charles-Louis de Socondat. Do espírito das leis. Tradução, introdução e notas de Edson Bini. Bauru, SP: EDIPRO, 2004. (Série Clássicos)

ROVIELLO, Anne-Marie. Senso comum e modernidade em Hannah Arendt. Trad. Bénédicte Houart e João Filipe Marques. Lisboa: Inst. Piaget, 1987.

SCHIO, Sônia Maria. Hannah Arendt: história e liberdade (da ação à reflexão). Caxias do Sul, RS: EdUCS, 2006.

VETÖ, Miklos. Coerência e terror: introdução à filosofia política de Hannah Arendt. Filosofia Política 5. Porto Alegre/São Paulo: L\&PM, 1989. (68-100). 